\title{
A NEW PLASTIC CORRECTION FOR THE STRESS INTENSITY FACTOR OF AN UNDERCLAD DEFECT IN A PWR VESSEL SUBMITTED TO A PRESSURISED THERMAL SHOCK
}

S. Marie

Commissariat à l'Energie Atomique

CEA/DEN/DM2S/SEMT/LISN

CEA Saclay

91191 Gif sur Yvette Cedex

France
M. Nédélec

Institut de Radioprotection et de Sûreté Nucléaire

IRSN/DSR/SAMS

B.P. 6 - 92265 Fontenay-aux-Roses Cedex

France

\section{$\underline{\text { Abstract }}$}

For the assessment of an under-clad defect in a vessel submitted to a cold pressurized thermal shock, plasticity is considered through the amplification $\beta$ of the elastic stress intensity factor $\mathrm{K}_{\mathrm{I}}$ in the ferritic part of the vessel. An important effort has been made recently by CEA to improve the analytical tools in the frame of R\&D activities funded by IRSN. The current solution in the French RSE-M code has been developed from fitting F.E. calculation results. A more physical solution is proposed in this paper. This takes into account two phenomena : the amplification of the elastic $\mathrm{K}_{\mathrm{I}}$ due to the plasticity in the cladding and a plastic zone size correction in the ferritic part.

The first correction has been established by representing the cladding plasticity by an imposed displacement on the crack lips at the interface between the cladding and the ferritic vessel. The corresponding elastic stress intensity factor is determined from the elastic plane strain asymptotic solution for the opening displacement. Plasticity in the ferritic steel is considered through a classical plastic zone size correction. 
The application of the solution to axisymmetric defects is first checked. The case of semielliptical defects is also investigated. For the correction determined at the interface between the cladding and the ferritic vessel, an amplification of the correction proposed for the deepest point is determined from a fitting of the 3D F.E. calculation results. It is also shown that the proposition of RSE-M which consists in applying the same $\beta$ correction at the deepest point and the interface point is not suitable.

The applicability to a thermal shock, eventually combined with an internal pressure has been verified. For the deepest point, the proposed correction leads to similar results to the RSE-M method, but presents an extended domain of validity (no limit on the crack length are imposed).

\section{Keywords}

Plastic correction, stress intensity factor KI, Thermal shock, internal pressure, PTS, Vessel, Cladding, RPV.

\section{Nomenclature}

A crack tip in the ferritic vessel - deepest point for a semi-elliptical defect

a Crack depth

B crack tip in the cladding

2c Crack width at the interface

C semi-elliptical defect point at the cladding-ferritic vessel interface

$\mathrm{C}_{\mathrm{p}} \quad$ Specific heat

$\mathrm{h} \quad$ Thickness of the ferritic vessel

$\mathrm{H} \quad$ Heat transfer coefficient $\left(\mathrm{W} / \mathrm{m}^{2} /{ }^{\circ} \mathrm{C}\right)$

J $\quad$ Rice integral $\left(\mathrm{kJ} / \mathrm{m}^{2}\right)$ 
$\mathrm{K}_{\mathrm{I}} \quad$ Elastic stress intensity factor $\left(\mathrm{MPa} \cdot \mathrm{m}^{0.5}\right)$

$\mathrm{K}_{\mathrm{I}, \mathrm{A}} \quad$ Crack tip A elastic stress intensity factor (MPa.m ${ }^{0.5}$ )

$\mathrm{K}_{\mathrm{J}} \quad$ Elastic-plastic stress intensity factor (MPa.m ${ }^{0.5}$ ), deduced from $\mathrm{J}$

$\mathrm{k}_{\mathrm{m}} \quad$ shape function relating imposed membrane stress to $\delta_{\mathrm{el}}$

r $\quad$ Cladding thickness

$\mathrm{r}_{\mathrm{yA}}, \mathrm{r}_{\mathrm{yB}} \quad$ Plastic zone size at crack tip A and B

$\mathrm{R}_{\mathrm{e}} \quad$ Outer radius of vessel

$\mathrm{R}_{\mathrm{i}} \quad$ Inner radius of vessel

$\mathrm{R}_{0} \quad$ Radius of the interface

$\mathrm{S}_{\mathrm{B}} \quad$ ligament size in the cladding

$\mathrm{u}_{\mathrm{y}} \quad$ Opening displacement along the crack lip

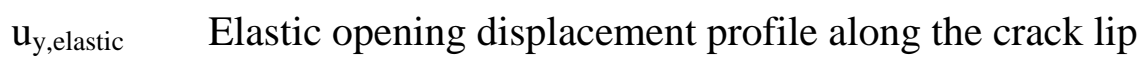

$\mathrm{u}_{\mathrm{y}, \mathrm{el} \_ \text {max }} \quad$ Maximum opening displacement for the elastic profile along the crack lip

$\mathrm{u}_{\mathrm{y}, \mathrm{pl}}(\mathrm{x}=0) \quad$ Opening displacement at the interface related to the cladding plasticity

x Radial position

$\beta \quad$ Stress intensity factor amplification due to plasticity

$\beta_{\mathrm{A}}, \beta_{\mathrm{C}} \quad \beta$ for the defect deepest point and the interface point of a semi-elliptical defect

$\Delta \mathrm{T}_{1} \quad$ temperature linear through thickness variation in the vessel

$\delta_{\mathrm{el}} \quad 2 \mathrm{u}_{\mathrm{y}, \mathrm{el} \_ \text {max }}$

$\lambda \quad$ Thermal conductivity

$v \quad$ Poisson's ratio

$\sigma_{\mathrm{m}} \quad$ Imposed membrane stress

$\sigma_{\mathrm{yB}} \quad$ Cladding yield stress 


\section{$1 \underline{\text { Introduction }}$}

For Reactor Pressure Vessel (RPV) integrity demonstration, a defect assessment has to be performed considering a Pressurized cold Thermal Shock (PTS). The RPV is a ferritic vessel with an austenitic cladding inside. Several approaches are proposed in different reference codes and standards. Usually, the analyses are based on analytical methods. An important effort has been made recently by CEA to improve these tools in the frame of R\&D activities funded by IRSN. A complete analytical solution has been developed for the through-thickness temperature and thermal stresses in a cladded vessel submitted to a thermal shock [1]. A relation for internal pressure stresses has been proposed in [2]. These stress equations have been linearised close to the interface between the cladding and the ferritic part of the vessel [2]. An elastic stress intensity factor compendium has also been proposed [2] for under-clad and through-clad defects. The expression of the elastic stress intensity factor is based on a polynomial representation of the through-thickness opening stress up to the $4^{\text {th }}$ order in the ferritic vessel. Corresponding influence functions are tabulated as functions of $\mathrm{a} / \mathrm{c}$ and $\mathrm{a} / \mathrm{r}$ ratios : due to the important curvature radius, the compendium has been developed from 3D F.E. elastic calculations considering only cracked plates. The difference of behaviour between the cladding and the vessel is taken into account in the tables through the Young's modulus ratio.

This paper deals with the influence of plasticity: in the RSE-M code [3], plasticity is represented through an amplification of the elastic stress intensity factor for underclad defects. This $\beta$ amplification depends on the plastic zone radius in the cladding and the cladding thickness. This correction has been fitted from 2D axisymmetric F.E. calculations and is valid for a limited range of defect sizes [3,4]. The influence of the defect length is also not taken into account in the expression of the correction. A new formulation is proposed in this paper for axisymmetric and semi-elliptical underclad defects. This amplification is based on the identification of the different effects of the plasticity 
and is first developed for axisymmetric defects. The transferability of the correction to semi-elliptical defects is then adresses and a modification is proposed for the point in the ferritic part at the interface.

\section{$2 \underline{\text { The } K} \underline{\text { RSE-M method }}$}

\subsection{DOMAIN OF VALIDITY}

The RSE-M method [3] adresses an underclad defect located in a ferritic steel vessel with an austenitic clad submitted to :

- $\quad$ a thermal shock applied to the internal surface of the vessel, with limited internal pressure

- $\quad$ an internal pressure only.

The method is valid if $\left|\frac{\mathrm{r}-\mathrm{s}_{\mathrm{B}}}{\mathrm{r}}\right| \leq 0,2, \frac{\mathrm{a}}{\mathrm{r}} \leq 3$ and $\frac{\mathrm{a}}{\mathrm{h}} \leq \frac{1}{10}$

where $r$ is the cladding thickness and $s_{B}$ is the ligament length in the cladding (figure 1).

\subsection{CONTINUOUS UNDERCLAD DEFECTS}

For a circumferential axisymmetric or a continuous longitudinal defect, the elastic-plastic stress intensity factor is calculated following these equations :

The plastic zone radius $r_{B}$ defined at the crack tip $B$ in the cladding (see figure 1) is given by :

$$
\mathrm{r}_{\mathrm{yB}}=\frac{1}{6 \pi}\left[\frac{\mathrm{K}_{\mathrm{elB}}}{\sigma_{\mathrm{yB}}}\right]^{2}
$$

where $\mathrm{K}_{\mathrm{elB}}$ is the elastic stress intensity factor at point $\mathrm{B}$ and $\sigma_{\mathrm{yB}}$ is the cladding yield stress. During the load history, the elastic stress intensity factor at crack tip A increases and can reach a maximum value. Up to this maximum value, the corrected stress intensity factor $\mathrm{K}_{\mathrm{ep}}$ is deduced from : 
- at point A (crack tip in the ferritic part) : $\mathrm{K}_{\mathrm{epA}}=\beta_{\mathrm{A}} \cdot \mathrm{K}_{\mathrm{elA}}$ with $\beta_{\mathrm{A}}=1+0,5 \cdot \tanh \left(\frac{36 \mathrm{r}_{\mathrm{yB}}}{\mathrm{s}_{\mathrm{B}}}\right)$

- at point B (crack tip in the cladding) : $\mathrm{K}_{\mathrm{epB}}=\beta_{\mathrm{B}} \cdot \mathrm{K}_{\mathrm{elB}}$ with $\beta_{\mathrm{B}}=1+0,3 \cdot \tanh \left(\frac{36 \mathrm{r}_{\mathrm{yB}}}{\mathrm{s}_{\mathrm{B}}}\right)$

Once the maximum value of $\mathrm{K}_{\mathrm{el}}$ reached, the corrected stress intensity factor $\mathrm{K}_{\mathrm{ep}}$ is then obtained from :

- at point A : $\quad \mathrm{K}_{\mathrm{epA}}=\mathrm{K}_{\mathrm{elA}}+\left(\mathrm{K}_{\mathrm{epA}}-\mathrm{K}_{\mathrm{elA}}\right)_{\max }$ where $\left(\mathrm{K}_{\mathrm{epA}}-\mathrm{K}_{\mathrm{elA}}\right)_{\max }$ is the value of $\left(\mathrm{K}_{\mathrm{epA}}-\mathrm{K}_{\mathrm{elA}}\right)$ when the maximum $\mathrm{K}_{\mathrm{elA}}$ is reached.

- at point B : $\quad \mathrm{K}_{\mathrm{epB}}=\mathrm{K}_{\mathrm{elB}}+\left(\mathrm{K}_{\mathrm{epB}}-\mathrm{K}_{\mathrm{elB}}\right)_{\max }$ where $\left(\mathrm{K}_{\mathrm{epB}}-\mathrm{K}_{\mathrm{elB}}\right)_{\max }$ is the value of $\left(\mathrm{K}_{\mathrm{epB}}-\mathrm{K}_{\mathrm{elB}}\right)$ when the maximum $\mathrm{K}_{\mathrm{elB}}$ is reached.

\subsection{FINITE LENGTH UNDERCLAD DEFECTS}

For circumferential or longitudinal semi-elliptic defects with a defect characterized by its depth a and total length 2c (with $c \geq a$ ), the same correction is applied at the interface of the vessel-cladding (point C) as at the deepest point (point A) :

$$
\mathrm{K}_{\mathrm{epC}}=\beta_{\mathrm{C}} \cdot \mathrm{K}_{\mathrm{elC}} \quad \text { with } \quad \beta_{\mathrm{C}}=1+0,5 \cdot \tanh \left(\frac{36 \mathrm{r}_{\mathrm{yB}}}{\mathrm{s}_{\mathrm{B}}}\right)
$$

when the maximum value of $\mathrm{K}_{\mathrm{elC}}$ has been reached during the load history, $\mathrm{K}_{\mathrm{epC}}$ is deduced from $\mathrm{K}_{\mathrm{epC}}=\mathrm{K}_{\mathrm{elC}}+\left(\mathrm{K}_{\mathrm{epC}}-\mathrm{K}_{\mathrm{elC}}\right)_{\max }$ 


\section{F.E. calculation data base}

To support this work, a F.E. calculation data base has been compiled. This includes 2D and 3D F.E. calculation results.

\subsection{PRESENTATION OF MODELS}

2D models correspond to a circumferential axisymmetric defect. The crack tip B (in the cladding) is located at the interface. A fine mesh is used around the defect to obtain accurate results. For thermal shock analysis, the geometry is an academic case, far from the sizes relevant to an RPV : $R_{i}=10000$ $\mathrm{mm}, \mathrm{h}=250 \mathrm{~mm}$ and $\mathrm{r}=10 \mathrm{~mm}$. The defect length, normalised by the cladding thickness, is between 0.625 and 2.5 .

3D defects have a semi-elliptical shape (figure 2) with a longitudinal orientation. Particular attention has been paid to the crack front mesh (figure 2). Several ratios of $\mathrm{a} / \mathrm{r}$ and $\mathrm{c} / \mathrm{a}$ have been considered. 3 geometries have been defined :

- $\mathrm{G} 1: \mathrm{R}_{\mathrm{i}}=10000 \mathrm{~mm}, \mathrm{~h}=250 \mathrm{~mm}$ and $\mathrm{r}=10 \mathrm{~mm}$,

- $\quad \mathrm{G} 2: \mathrm{R}_{\mathrm{i}}=2500 \mathrm{~mm}, \mathrm{~h}=250 \mathrm{~mm}$ and $\mathrm{r}=10 \mathrm{~mm}$,

- $\quad \mathrm{G} 3: \mathrm{R}_{\mathrm{i}}=2500 \mathrm{~mm}, \mathrm{~h}=250 \mathrm{~mm}$ and $\mathrm{r}=6 \mathrm{~mm}$.

\subsection{MATERIAL PROPERTIES}

For thermal characteristics, 2 sets of values have been used. For 2D analyses, no temperature dependence is considered. Table 1 gives the thermal constants for the 2D calculations. For 3D F.E. analyses, thermal properties are functions of the temperature. Table 2 gives the variations, in which a linear interpolation is performed by the F.E. code. In all calculations the density is $7600 \mathrm{~kg} / \mathrm{m}^{3}$.

For mechanical properties, 3 combinations are considered : 
- $\quad$ M1 : cladding and ferritic steel have the same material properties, temperature independent with a bilinear stress-strain curve (Table 3).

- M2 : cladding and ferritic steel show different bilinear behaviour, also temperature independent (Table 3).

- M3 : the behaviour of the materials is bilinear and depends on temperature (Table 4). Only the tangent modulus $\mathrm{E}_{\mathrm{T}}$ is constant and is the same for the two materials (2000 MPa.mm/mm).

\subsection{LOADING CONDITIONS}

For 2D calculations, only a thermal shock is considered. 3 scenarii have been used :

- An increasing linear through-thickness thermal gradient $\Delta \mathrm{T}_{1}$.

- A 'smooth' conventional linear thermal shock : the fluid temperature decreases from $286^{\circ} \mathrm{C}$ to $7^{\circ} \mathrm{C}$ in 2000 seconds with a constant heat transfer coefficient $\mathrm{H}=20000 \mathrm{~W} / \mathrm{m}^{2} .{ }^{\circ} \mathrm{C}$.

- A 'fast' conventional linear thermal shock : the fluid temperature decreases from $286^{\circ} \mathrm{C}$ to $7^{\circ} \mathrm{C}$ in 50 seconds with a constant heat transfer coefficient $\mathrm{H}=20000 \mathrm{~W} / \mathrm{m}^{2}{ }^{\circ} \mathrm{C}$.

For 3D configurations, only one quarter of the vessel is modelled. A thermal shock alone or thermal shock combined with a constant internal pressure is modelled. 2 scenarii are used for the thermal loading :

- A linear thermal shock with a constant heat transfer coefficient $\mathrm{H}=20000 \mathrm{~W} / \mathrm{m}^{2} .{ }^{\circ} \mathrm{C}$ (thermal shock 'CL', Figure 3),

- A realistic thermal shock with a time dependant heat transfer coefficient $\mathrm{H}$ (thermal shock 'S', Figure 4) 


\subsection{CALCULATION MATRIX}

The different configurations in terms of geometry, material and loading have been described in section 3.1-3.3. Tables 5 and 6 present all combinations available in the data base for 2D and 3D F.E. calculations. This represents 18 2D cases and 42 3D cases.

\section{Amplification of the elastic stress intensity factor in the ferritic vessel due to}

\section{cladding plasticity}

A simplified representation of the elastic problem is to consider a surface crack subjected to two superposed loadings: the nominal loading and an imposed displacement on the part of the crack lips corresponding to the ligament in the cladding. This closure displacement reduces the ferritic crack tip loading. The superposition of these two loadings is taken into account in the elastic stress intensity factor compendium [2].

The elastic-plastic $\mathrm{J}$ value at the crack tip in the ferritic part results from two main phenomena which should be considered to estimate accurately the plastic amplification :

- In the real problem, the cladding shows a significant plasticity when the ferritic part remains nearly elastic. This plasticity could be represented by an opening displacement imposed on the crack tip located at the interface, which increases the ferritic crack tip loading, and of course the corresponding elastic stress intensity factor.

- Even if the ferritic vessel remains globally elastic, the crack tip in this domain is in small scale yielding which induces a second well-known amplification. 


\subsection{SIMPLIFIED PROBLEM}

First, to determine easily the amplification of the elastic stress intensity factor in the ferritic part related to the plasticity in the cladding, an axisymmetric under-clad defect is considered, subjected to a nominal uniform membrane stress.

The vessel is $250 \mathrm{~mm}$ thick and the internal radius is $2500 \mathrm{~mm}$ (without the cladding). The cladding thickness is 5,10 or $20 \mathrm{~mm}$ and the total defect depth varies between $3.125 \mathrm{~mm}(\mathrm{a} / \mathrm{h}=$ $0.0125)$ to $100 \mathrm{~mm}(\mathrm{a} / \mathrm{h}=0.4)$.

2D F.E. calculations are performed considering elastic behaviour for the two materials, or an elastic ferritic vessel and an elastic-plastic cladding (bi-linear stress-strain curve with a yield stress at $360 \mathrm{MPa})$.

This simple configuration aims to check if the amplification in the ferritic part could effectively be represented by an imposed opening displacement on the crack lips. For different cases (elastic or elastic-plastic cladding) and load levels, the crack opening displacement along the crack lips is determined. Figure 5 presents the variations obtained for a $20 \mathrm{~mm}$ thick cladding and a crack length of $50 \mathrm{~mm}$. The corresponding nominal stress level is $871 \mathrm{MPa}$.

The elastic profile $\mathrm{u}_{\mathrm{y} \text {,elastic }}$ is as expected close to an elliptical shape. The elastic-plastic profile

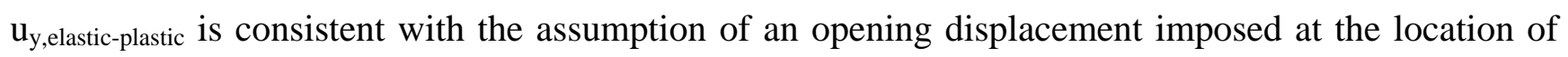
the crack tip at the interface, related to the plasticity in the cladding. Figure 5 shows also the difference between these two variations, which appears to be close to a $\mathrm{r}^{0.5}$ law. To complete these observations, the elastic profile of the plane strain asymptotic solution, added to the elastic profile obtained from the F.E. analysis $\left(\mathrm{u}_{\mathrm{y}, \text { elastic }}\right)$, is also drawn $\left(\mathrm{u}_{\mathrm{y}, \text { simplified }}(\mathrm{x})\right)$, using an optimised value of the opening displacement at the interface $\mathrm{u}_{\mathrm{y}, \mathrm{pl}}(\mathrm{x}=0)$ to minimize the difference with the F.E. elastic-plastic curve :

$$
\mathrm{u}_{\mathrm{y}, \text { simplified }}(\mathrm{x})=\mathrm{u}_{\mathrm{y}, \text { elastic }}(\mathrm{x})+\mathrm{u}_{\mathrm{y}, \mathrm{pl}}(\mathrm{x}=0) \cdot(50-\mathrm{x})^{0,5}
$$


where $\mathrm{x}$ represents the distance to the interface between the ferritic vessel and the cladding. For the configuration presented in Figure $5, \mathrm{u}_{\mathrm{y}, \mathrm{pl}}(\mathrm{x}=0)=0.21 \mathrm{~mm}$. This simplified profile appears to be in very good agreement with the F.E. elastic-plastic profile. Then, if we are able to estimate $\mathrm{u}_{\mathrm{y}, \mathrm{pl}}(\mathrm{x}=0)$, the corresponding stress intensity factor $\mathrm{K}_{\mathrm{I}, \mathrm{A} \_ \text {upl }}$ could be deduced from the plane strain asymptotic solution, and then the amplification of the elastic stress intensity factor $\mathrm{K}_{\mathrm{I}, \mathrm{A}}$ in the ferritic part due to the cladding plasticity.

This result has been confirmed on all other configurations tested.

\subsection{CALCULATION OF THE OPENING DISPLACEMENT DUE TO CLADDING PLASTICITY}

First a search is made for an analytical solution for the opening displacement profile for the full elastic configuration. Taking into account the vessel dimensions, the problem could be compared to the case of a plate containing a sharp slot.

For the plane strain situation, with a centre cracked plate subjected to a nominal membrane stress $\sigma_{\mathrm{m}}$, appendix A16 [5] of the RCC-MR code proposes a solution considering an elliptical opening profile. If the total length of the slot is $2 . c_{\mathrm{L}}$, the maximum total opening displacement $\delta_{\mathrm{el}}$ is given by :

$$
\delta_{\mathrm{el}}=\frac{4 \cdot \mathrm{C}_{\mathrm{L}}}{\mathrm{E}} \cdot \mathrm{k}_{\mathrm{m}} \cdot \sigma_{\mathrm{m}}
$$

In our problem, 2. $c_{\mathrm{L}}=\mathrm{a}$. If we neglect the fact that the crack is off-centre and consider small defects $(\mathrm{a} / \mathrm{h}<0.4), \mathrm{k}_{\mathrm{m}}$ can be simplified to 1 (according to values proposed in appendix A16 [5]). The maximum opening displacement here $\mathrm{u}_{\mathrm{y}, \mathrm{el} \_ \text {max }}\left(=\delta_{\mathrm{e}} / 2\right)$ is then deduced from :

$$
\mathrm{u}_{\mathrm{y}, \mathrm{el} \_ \text {max }}=\frac{\mathrm{a}}{\mathrm{E}} \cdot \sigma_{\mathrm{m}}
$$

and the elastic profile is represented by the classical ellipse equation : 


$$
\left(\frac{\mathrm{u}_{\mathrm{y}}}{\mathrm{u}_{\mathrm{y}, \mathrm{e} \_ \text {max }}}\right)^{2}+\left(\frac{\mathrm{x}-\mathrm{a} / 2}{\mathrm{a} / 2}\right)^{2}=1
$$

Figure 6 compares successfully this equation to the F.E. profile obtained with the full elastic model.

To estimate the opening displacement related to cladding plasticity, we first consider that the cladding is in small scale yielding. An extended crack length is then taken into account using the plastic zone size $\mathrm{r}_{\mathrm{y}, \mathrm{B}}$ in plane strain:

$$
\mathrm{r}_{\mathrm{y}, \mathrm{B}}=\frac{1}{6 \pi} \cdot\left(\frac{\mathrm{K}_{\mathrm{I}, \mathrm{B}}}{\sigma_{\mathrm{y}, \text { cladding }}}\right)^{2}
$$

where $\mathrm{K}_{\mathrm{I}, \mathrm{B}}$ is the elastic stress intensity factor for the crack tip at the interface and $\sigma_{\mathrm{y} \text {,cladding }}$ is the cladding yield stress. We propose then to consider a dilation of the opening displacement profile. Only the half part near the cladding is concerned, as shown in Figure 7. The equation of this extended profile is then :

$$
\left(\frac{\mathrm{u}_{\mathrm{y}}(\mathrm{x})}{\mathrm{u}_{\mathrm{y}, \mathrm{el}_{-} \text {max }}}\right)^{2}+\left(\frac{\mathrm{x}-\mathrm{a} / 2}{\mathrm{a} / 2+\mathrm{r}_{\mathrm{y}, \mathrm{B}}}\right)^{2}=1 \text { with } \mathrm{u}_{\mathrm{y}, \mathrm{el}_{-} \max }=\frac{\mathrm{a}}{\mathrm{E}} \cdot \sigma_{\mathrm{m}} \text { and }-\mathrm{r}_{\mathrm{y}} \leq \mathrm{x} \leq \mathrm{a} / 2
$$

The searched opening displacement is then given by equation (10) for $\mathrm{x}=0$, which corresponds to the interface :

$$
\mathrm{u}_{\mathrm{y}, \mathrm{pl}}=\mathrm{u}_{\mathrm{y}}(\mathrm{x}=0)=\mathrm{u}_{\mathrm{y}, \mathrm{e} \mathrm{e}_{-} \max } \sqrt{1-\left(\frac{\mathrm{a}}{\mathrm{a}+2 \cdot \mathrm{r}_{\mathrm{y}, \mathrm{B}}}\right)^{2}}
$$

The determination of $\mathrm{u}_{\mathrm{y}, \mathrm{pl}}$ is based on the calculation of $\mathrm{u}_{\mathrm{y}, \mathrm{el} \_ \text {max. }}$. When the loading condition is more complex than an uniform stress, it is proposed to determined an equivalent uniform membrane stress $\sigma_{\mathrm{m}}$ from the stress intensity factor $\mathrm{K}_{\mathrm{I}, \mathrm{A}}$ in the ferritic part : 


$$
\sigma_{\mathrm{m}}=\frac{\mathrm{K}_{\mathrm{I}, \mathrm{A}}}{\sqrt{\pi \cdot \mathrm{a} / 2}}
$$

\subsection{STRESS INTENSITY FACTOR AMPLIFICATION AT THE CRACK TIP IN THE FERRITIC PART}

Knowing the imposed displacement at the distance a from the crack tip in the ferritic side related to cladding plasticity, the corresponding stress intensity factor $\mathrm{K}_{\mathrm{I}, \mathrm{A} \_ \text {uy,pl }}$ is easily determined for the asymptotic plane strain solution :

$$
\mathrm{K}_{\mathrm{I}, \mathrm{A} \_\mathrm{u}_{\mathrm{y}, \mathrm{pl}}}=\frac{2 \mu}{\kappa+1} \cdot \sqrt{\frac{2 \pi}{\mathrm{a}}} \cdot \mathrm{u}_{\mathrm{y}, \mathrm{pl}}
$$

$$
\text { with : } \quad \kappa=3-4 . v \quad \mu=\frac{\mathrm{E}}{2 .(1-v)} \quad \text { and } \quad \mathrm{u}_{\mathrm{y}, \mathrm{pl}}=\frac{\mathrm{K}_{\mathrm{I}, \mathrm{A}}}{\mathrm{E}} \cdot \sqrt{\frac{2 \mathrm{a}}{\pi}} \sqrt{1-\left(\frac{\mathrm{a}}{\mathrm{a}+2 \cdot \mathrm{r}_{\mathrm{y}, \mathrm{B}}}\right)^{2}}
$$

that leads to :

$$
\mathrm{K}_{\mathrm{I}, \mathrm{A} \_\mathrm{u}_{\mathrm{y}, \mathrm{pl}}}=\frac{\mathrm{K}_{\mathrm{I}, \mathrm{A}}}{2 \cdot\left(1-v^{2}\right)} \cdot \sqrt{1-\left(\frac{1}{1+\frac{2 \cdot \mathrm{r}_{\mathrm{y}, \mathrm{B}}}{\mathrm{a}}}\right)^{2}}
$$

The amplification $\beta$ of the elastic stress intensity factor $\mathrm{K}_{\mathrm{I}, \mathrm{A}}$ related to the cladding plasticity is then :

$$
\beta=\frac{\mathrm{K}_{\mathrm{I}, \mathrm{A}}+\mathrm{K}_{\mathrm{I}, \mathrm{A} \_\mathrm{u}_{\mathrm{y}, \mathrm{pl}}}}{\mathrm{K}_{\mathrm{I}, \mathrm{A}}}=1+\frac{1}{2 \cdot\left(1-v^{2}\right)} \cdot \sqrt[1]{1-\left(\frac{1}{\left.1+\frac{2 \cdot \mathrm{r}_{\mathrm{y}, \mathrm{B}}}{\mathrm{a}}\right)^{2}}\right.}
$$


In contrast to the RSE-M solution [3], the amplification proposed here depends on crack length. It is also interesting to note that the maximum value of the proposed solution is $\left[1+0.5 /\left(1-v^{2}\right)\right]$ and equals 1.55 for $v=0.3$, which is very near to the fitted limit value proposed by the RSE-M relation : 1.5 . The correction is only a function of the crack length and the plastic zone size in the cladding, which is a representation of the ratio between the stress intensity factor calculated for the crack tip at the interface and the cladding yield stress. The assumption about the stress distribution (uniform nominal stress) is not clearly visible in this final relation, but the transferability of the results to the thermal shock situation has to be checked.

\subsection{VERIFICATION OF THE PROPOSED SOLUTION}

To check the validity of the proposed equation, the stress intensity factor $K_{I, A}$ for the ferritic crack tip has been calculated for the previous 2D F.E. calculations with elastic behaviour of the ferritic steel and elastic-plastic behaviour for the cladding. For these calculations, the load is an increasing nominal uniform stress.

Some results are presented in Figure 8, representative of the application of the proposed solution, validated on a larger number of configurations :

- $20 \mathrm{~mm}$ thick cladding, relative crack depth $\mathrm{a} / \mathrm{h}=0.0125,0.025,0.05,0.1,0.2$ and 0.4 ,

- $1 \mathrm{~mm}$ thick cladding, relative crack depth $\mathrm{a} / \mathrm{h}=0.0125,0.025,0.05,0.1$ and 0.2 ,

- $5 \mathrm{~mm}$ thick cladding, relative crack depth $\mathrm{a} / \mathrm{h}=0.0125,0.025,0.05,0.1$ and 0.2 .

The proposed solution provides a good estimate of the amplification. In particular, the amplification becomes conservative when the defect size (or cladding thickness) decreases for a given cladding thickness (or defect size), as shown in Figures 8-c and d. This is related to the opening 
displacement being overestimated when there is a significant plasticity in the cladding : this stage is reached faster for a small cladding thickness or a small defect depth for a given load level.

\section{Pressurised thermal shock analysis}

This section deals with the applicability of the proposed solution to the thermal shock problem, eventually with an internal pressure. In this case, the behaviour of the ferritic vessel is also elasticplastic.

\subsection{AMPLIFICATION DUE TO SMALL SCALE PLASTICITY AT THE FERRITIC CRACK TIP}

As noted previously, the proposed amplification is only related to the cladding plasticity. It is suggested that a plastic zone size correction is added to account for plasticity at the crack tip in the ferritic part, which is assumed to remain in small scale yielding. The final new $\beta$ correction is then :

$$
\beta=\frac{\mathrm{K}_{\mathrm{J}, \mathrm{A}}}{\mathrm{K}_{\mathrm{I}, \mathrm{A}}}=\left[1+\frac{1}{2 \cdot\left(1-v^{2}\right)} \cdot \sqrt{1-\left(\frac{1}{1+\frac{2 \cdot \mathrm{r}_{\mathrm{y}, \mathrm{B}}}{\mathrm{a}}}\right)^{2}}\right] \cdot \sqrt{\frac{\mathrm{a} / 2+\mathrm{r}_{\mathrm{y}, \mathrm{A}}}{\mathrm{a} / 2}}
$$

where $r_{y, A}$ and $r_{y, B}$ are the plane strain plastic zone radii in the ferritic part and in the cladding, respectively, calculated from the elastic stress intensity factors for the complete elastic problem.

\subsection{THERMAL SHOCK APPLIED TO A VESSEL CONTAINING AN AXISYMMETRIC DEFECT}

In this section, the proposed solution is checked for a more complex configuration : the loading is a realistic thermal shock and elastic-plastic behaviour is considered for both the cladding and the ferritic steel. The cases investigated are summarised in Table 5. Only the increasing phase of the stress intensity factor $\mathrm{K}_{\mathrm{J}}$ deduced from the $\mathrm{J}$ integral calculation is considered. 
Figures 9-a and b present some typical results for an homogenous vessel, and Figure 9-c and d for a bi-material vessel. No influence of the material properties combination is noted on results obtained with the proposed method. For the RSE-M solution [3], the homogeneous case is always overestimated. A better agreement with the F.E. results is obtained for the bi-material configurations.

Figures 9-a and c presents results in the case of a smooth thermal shock (small dT/dt) : the proposed solution gives in these case accurate predictions. For hard thermal shock (high dT/dt), the proposed solution is slightly pessimistic : this is probably due to the a uniform imposed stress assumption (equation 12) which is not valid : for hard thermal shock, the temperature gradient (and then the related stress gradient) is strong near the cladding, at least at the beginning of the shock.

\subsection{CORRECTION FOR SEMI-ELLIPTICAL DEFECTS}

For a semi-elliptical under-clad defect, according to the RSE-M methodology [3], the same correction is applied at the deepest point and the point at the interface.

Figure 10 shows an example of the necessary correction from the ratio of the stress intensity factors from the elastic and elastic-plastic 3D F.E. calculations for the deepest point and the point at the interface. It is shown that the necessary $\beta$ correction at the interface $\left(\beta_{c}\right)$ is larger than the $\beta$ correction at the deepest point $\left(\beta_{\mathrm{A}}\right)$.

For all 3D F.E. results available in the data base, the 'ideal' $\beta_{c}$ correction is determined : this correction is calculated for the maximum value of $\mathrm{K}_{\mathrm{J}}$ at the interface. Figure 11 presents the variation of the ratio $\left(\beta_{\mathrm{c}} / \beta_{\mathrm{A}}\right)^{2}$ with the ratio c/a. It appears that the ratio $\beta_{\mathrm{c}} / \beta_{\mathrm{A}}$ is nearly independent of the cladding size or the behaviour of the materials. This information are already taken into account in $\beta_{\mathrm{A}}$. $\beta_{\mathrm{c}} / \beta_{\mathrm{A}}$ can then be given by : 


$$
\beta_{\mathrm{C}}=\beta_{\mathrm{A}} \cdot \sqrt{\min \left[1,7+0,23 \cdot\left(\frac{\mathrm{c}}{\mathrm{a}}-1\right) ; 2,5\right]}
$$

The application of the two corrections $\beta_{\mathrm{C}}$ and $\beta_{\mathrm{A}}$ gives good predictions, as illustrated in Figure 12. Conclusions for the predictions at the deepest point are similar to those for an axisymmetric defect. When the defect has a small c/a ratio, predictions overestimate the F.E. results (Figure 13-a). This case, the RSE-M solution leads to a good prediction of the correction at the deepest point. In our model, the correction is determined assuming an elliptical profile of the opening displacement, governed by the relation for an axisymmetric defect. When, the defect is too small, the defect is constrained by the surrounding material and shows a smaller opening displacement than given by the model : the correction is then too strong. When the ratio c/a increases, a comparable amplification to that for the axisymmetric defect is quickly obtained.

For the proposed solution same conclusion are obtained for the interface point : the predictions are in good agreement with the F.E. results (Figure 12-b), except when the defect is too small where the amplification is too severe (Figure 13-b). Whatever the case, the RSE-M solution leads to a too low value of the amplification at the interface point (Figures 12-b and 13-b).

\subsection{APPLICATION TO THE PRESSURIZED THERMAL SHOCK}

The application to combined thermal shock and internal pressure should not present specific difficulties (Figure 14), if small scale yielding condition is verified in the ferritic part, which corresponds to the real industrial problem. Indeed, if plasticity is too large, in particular due to the pressure, an interaction between the mechanical loading and the thermal loading has to be taken into account as reference [6] shows. The RSE-M solution seems to be also suitable in this situation for the deepest point. For the interface point, this solution is still too low. 


\section{$6 \underline{\text { Conclusions }}$}

This paper deals with the cold PTS analysis in a RPV containing an underclad defect, and more precisely with the plastic amplification of the elastic stress intensity factor in the ferritic vessel.

The RSE-M code [3] proposes a correction $\beta$ : this parameter is an amplification of the elastic stress intensity factor, developed from fitting of F.E. results. A more physical correction is proposed in this work : it takes into account the influence of the plasticity development in the cladding and the direct plastic amplification at the crack tip in the ferritic part.

The first correction has been established by representing the cladding plasticity by an imposed displacement on the crack lips at the interface between the cladding and the ferritic vessel. The corresponding elastic stress intensity factor is then determined from the elastic plane strain asymptotic solution for the opening displacement. Plasticity in the ferritic steel is considered through a classical plastic zone size correction.

The application of the solution obtained to axisymmetric defects is first checked. The case of semi-elliptical defects is then investigated. For the correction at the interface point of the defect, an amplification of the correction proposed for the deepest point is determined from a fitting of the 3D F.E. calculation results. It is also shown that the proposal in the RSE-M which applies the same $\beta$ correction at the deepest point and the interface point is not suitable.

The applicability to a thermal shock, eventually combined to an internal pressure has been verified. For the deepest point, the proposed correction leads to similar results to the RSE-M method except for semi-elliptical defects with a small c/a ratio where the method overestimate the amplification. 
The analysis of all cases allows a first idea of the domain of validity of the proposed solution : For axisymetric defect, the proposed method appears correct for a wide range of crack depth in the case of an ideal imposed nominal stress (good agreement has obtained up to ratio $\mathrm{a} / \mathrm{h}=0.4$ ). The solution becomes slightly conservative when the defect depth becomes small. It is also the case for small cladding thickness. Thermal shock loading has been tested and confirms to relevance of the solution, at least up to $\mathrm{a} / \mathrm{h}=0.1$. Realistic semi-elliptical defect has also been tested. When the ratio c/a is large (up to 8), the predictions are in good agreement with the F.E. results. On the contrary, the solution is conservative when the defect ratio c/a is small, due to the influence of the surrounding material on the crack opening displacement.

\section{Reference}

[1] Marie, S., 2004, 'Analytical expression of the thermal stresses in a vessel or pipe with cladding submitted to any thermal transient', International Journal of Pressure Vessels and Piping, Vol. 81, pp.303-312.

[2] S. Marie, S., Ménager, Y. and Chapuliot, S., 2005, 'Stress intensity factors for underclad and through clad defects in a reactor pressured vessel submitted to a pressurised thermal shock, International Journal of Pressure Vessels and Piping, vol. 82, pp 746-760.

[3] RSE-M, Annex 5.4, 2000, 'Règles de surveillance en exploitation des matériels mécaniques des îlots nucléaires REP’, AFCEN, Paris.

[4] Moinereau, D., Messelier-Gouze, C., Bedzikian, G., Ternon-morin, F., Meziere, Y., Faidy, C., Pellissier-Tanon, A., Vagner, J. and Guichard, D., 1998, ‘Some recent developments in 
French reactor pressure vessel structural integrity assessment', Pressure Vessels and Piping Conference, San Diego, USA.

[5] RCC-MR 2002 - Annexe A16, Tome I, Vol. Z, AFCEN, Paris.

[6] Marie, S. and Delaval, C., 2005, 'A new formulation to take into account the interaction between mechanical and thermal loadings for the analytical estimation of $\mathrm{J}$ parameter', Pressure Vessels and Piping Conference, Denver, USA. 


\section{Table Captions}

Table 1 : material thermal properties for the 2D F.E. calculations.

Table 2 : thermal properties for the 3D F.E. calculations.

Table 3 : mechanical properties for the configurations M1 and M2.

Table 4 : mechanical properties for the configuration M3. (*)Thermal expansion coefficient $\alpha$ between $20^{\circ} \mathrm{C} \& \mathrm{~T}\left(10^{-6} \mathrm{~K}^{-1}\right)$

Table 5 : F.E. calculation matrix for 2D axisymmetric configurations.

Table 6 : F.E. calculation matrix for 3D configurations. 


\begin{tabular}{|c|c|c|}
\hline & Ferritic steel & cladding \\
\hline$\lambda\left(\mathrm{W} \cdot \mathrm{m}^{-1} \cdot \mathrm{K}^{-1}\right)$ & 45.8 & 18.6 \\
\hline$C_{p}\left(J \cdot \mathrm{kg}^{-1} \cdot \mathrm{K}^{-1}\right)$ & 569 & 569 \\
\hline
\end{tabular}

Table 1 


\begin{tabular}{|l|c|c|c|c|c|}
\hline Temperature $T\left({ }^{\circ} \mathrm{C}\right)$ & 20 & 100 & 200 & 300 & 400 \\
\hline Ferritic vessel $: \lambda\left(\mathrm{W} \cdot \mathrm{m}^{-1} \cdot \mathrm{K}^{-1}\right)$ & 44 & 44 & 43 & 41 & 39 \\
\hline Ferritic vessel $: C_{p}\left(\mathrm{~J} \cdot \mathrm{kg}^{-1} \cdot \mathrm{K}^{-1}\right)$ & 460 & 490 & 520 & 560 & 610 \\
\hline Cladding $: \lambda\left(W \cdot \mathrm{m}^{-1} \cdot \mathrm{K}^{-1}\right)$ & 15 & 16 & 17 & 19 & 20 \\
\hline Cladding $: C_{p}\left(\mathrm{~J} \cdot \mathrm{kg}^{-1} \cdot \mathrm{K}^{-1}\right)$ & 500 & 500 & 520 & 540 & 590 \\
\hline
\end{tabular}

Table 2 


\begin{tabular}{|l|c|c|c|}
\hline \multicolumn{1}{|c|}{ Material } & Ferritic steel & $\begin{array}{c}\text { Cladding } \\
(\mathrm{M} 1)\end{array}$ & $\begin{array}{c}\text { Cladding } \\
(\mathrm{M} 2)\end{array}$ \\
\hline Young modulus $E(\mathrm{MPa})$ & 199000 & 199000 & 186000 \\
\hline Poisson's ratio $v$ & 0,3 & 0,3 & 0,3 \\
\hline Yield stress $\sigma_{0}(\mathrm{MPa})$ & 360 & 360 & 167 \\
\hline Tangent modulus $\mathrm{E}_{\mathrm{T}}(\mathrm{MPa} . \mathrm{mm} / \mathrm{mm})$ & 2000 & 2000 & 2000 \\
\hline Thermal expansion coefficient $\alpha$ between $20^{\circ} \mathrm{C} \& \mathrm{~T}\left(10^{-6} \mathrm{~K}^{-1}\right)$ & 10,9 & 10,9 & 16,4 \\
\hline
\end{tabular}

Table 3 


\begin{tabular}{|c|c|c|c|c|c|c|}
\hline \multicolumn{2}{|r|}{ Temperature $T\left({ }^{\circ}\right)$} & 20 & 100 & 200 & 300 & 400 \\
\hline \multirow{4}{*}{$\begin{array}{c}\text { ferritic } \\
\text { vessel }\end{array}$} & Young modulus $E(M P a)$ & 211000 & 206000 & 199000 & 192000 & 184000 \\
\hline & Poisson's ratio $v$ & 0,3 & 0,3 & 0,3 & 0,3 & 0,3 \\
\hline & Yield stress $\sigma_{0}(\mathrm{MPa})$ & 390 & 370 & 360 & 350 & 320 \\
\hline & Thermal expansion coefficient $\alpha$ & 11,7 & 12,7 & 13,2 & 13,6 & 14 \\
\hline \multirow{4}{*}{ cladding } & Young modulus $E(M P a)$ & 200000 & 194000 & 186000 & 179000 & 172000 \\
\hline & Poisson's ratio $v$ & 0,3 & 0,3 & 0,3 & 0,3 & 0,3 \\
\hline & Yield stress $\sigma_{0}(\mathrm{MPa})$ & 206 & 177 & 167 & 136 & 125 \\
\hline & Thermal expansion coefficient $\alpha$ & 15 & 16 & 17 & 17 & 18 \\
\hline
\end{tabular}

Table 4 


\begin{tabular}{|c|c|c|c|}
\hline Thermal loading & geometry & Material properties & $\mathrm{a} / \mathrm{r}$ \\
\hline Increasing $\Delta \mathrm{T}_{1}: 6$ & & & $0.625: 6$ \\
Smooth thermal shock: 6 & $\mathrm{G} 1: 18$ & $\mathrm{M} 1: 9$ & $1.25: 6$ \\
Sharp thermal shock :6 & & M2:9 & $2.5: 6$ \\
\hline
\end{tabular}

Table 5 


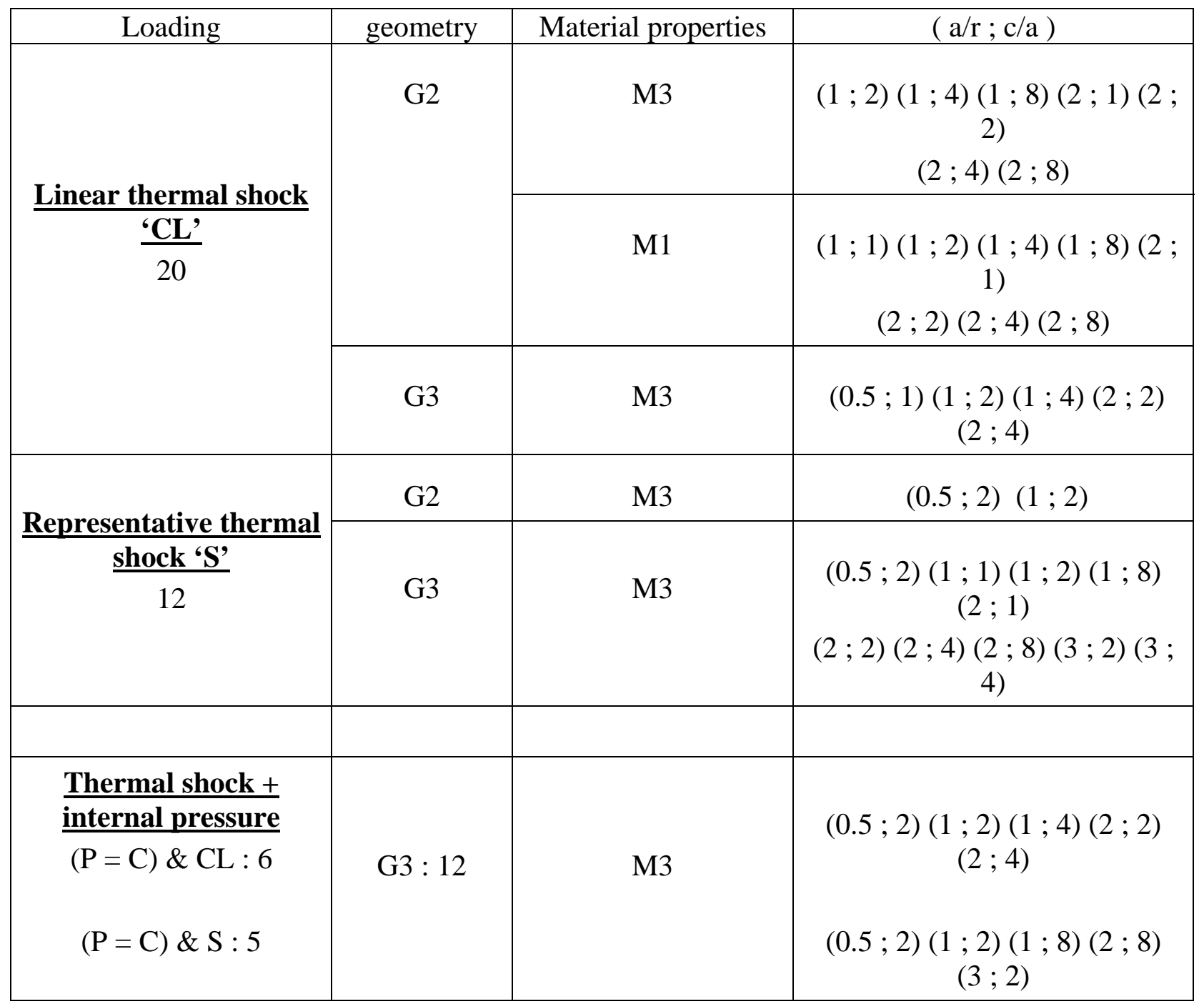

Table 6 


\section{Figure Captions}

Figure 1 : underclad defect description

Figure 2 : semi-elliptical defect mesh.

Figure 3 : Fluid temperature and heat transfer coefficient, H, variations for the loading sequence 'CL'.

Figure 4 : Fluid temperature and heat transfer coefficient, H, variations for the loading sequence ' $\mathrm{S}$ '.

Figure 5 : Opening displacement variations from F.E. calculation for a $20 \mathrm{~mm}$ thick cladding, a crack length of $50 \mathrm{~mm}$ and an imposed nominal uniform stress of $871 \mathrm{MPa}$.

Figure 6 : Prediction of the elastic opening displacement along the crack lip for a $20 \mathrm{~mm}$ thick cladding, a crack length of $50 \mathrm{~mm}$ and an imposed nominal uniform stress of $871 \mathrm{MPa}$.

Figure 7 : Illustration of the way to take into account the cladding plasticity to calculate imposed displacement related to the amplification of the stress intensity factor at the crack tip in the ferritic part.

Figure 8: Stress intensity factor amplification in the ferritic part due to cladding plasticity: comparison between F.E. results and the proposed analytical method.

Figure9 : Prediction of the stress intensity factor variation for a thermal shock in a pipe with an axisymmetric internal defect.

Figure 10 : Comparison of the stress intensity factor amplification due to plasticity at the deepest point and the interface point of the defect, deduced from F.E. elastic and elastic-plastic calculations $-(\mathrm{a} / \mathrm{r}=3$, $\mathrm{c} / \mathrm{a}=4, \mathrm{r}=6 \mathrm{~mm}$ - two-material vessel with a realistic thermal shock ' $\mathrm{S}$ ').

Figure 11 : Variation of the ratio of the amplification at the interface and the deepest points versus defect shape. 
Figure 12 : Application of the proposed method to the case of a thermal shock in a vessel including a semi-elliptical circumferential defect.

Figure $13: \mathrm{c} / \mathrm{a}=1$ Application of the proposed method to the case of a small semi-elliptical defect $(\mathrm{a} / \mathrm{r}$ $=1, \mathrm{c} / \mathrm{a}=1)$.

Figure 14 : Application of the proposed method to the case of a thermal shock with constant internal pressure of $15 \mathrm{MPa}$ in a vessel including a semi-elliptical circumferential defect $(\mathrm{a} / \mathrm{r}=3, \mathrm{c} / \mathrm{a}=2, \mathrm{r}=6$, thermal shock ' $\mathrm{S}$ '). 


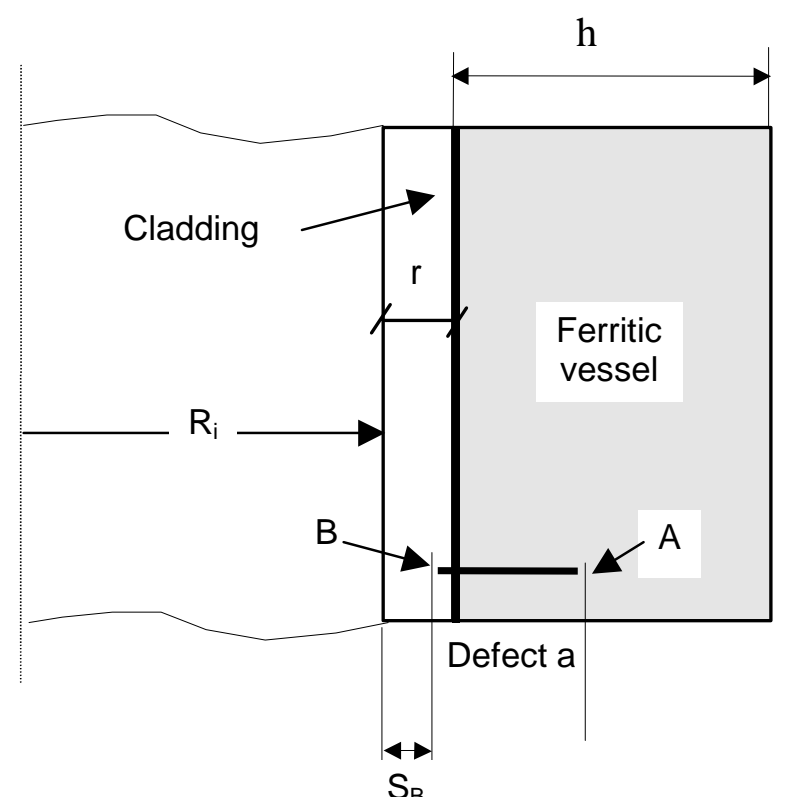

Figure 1 

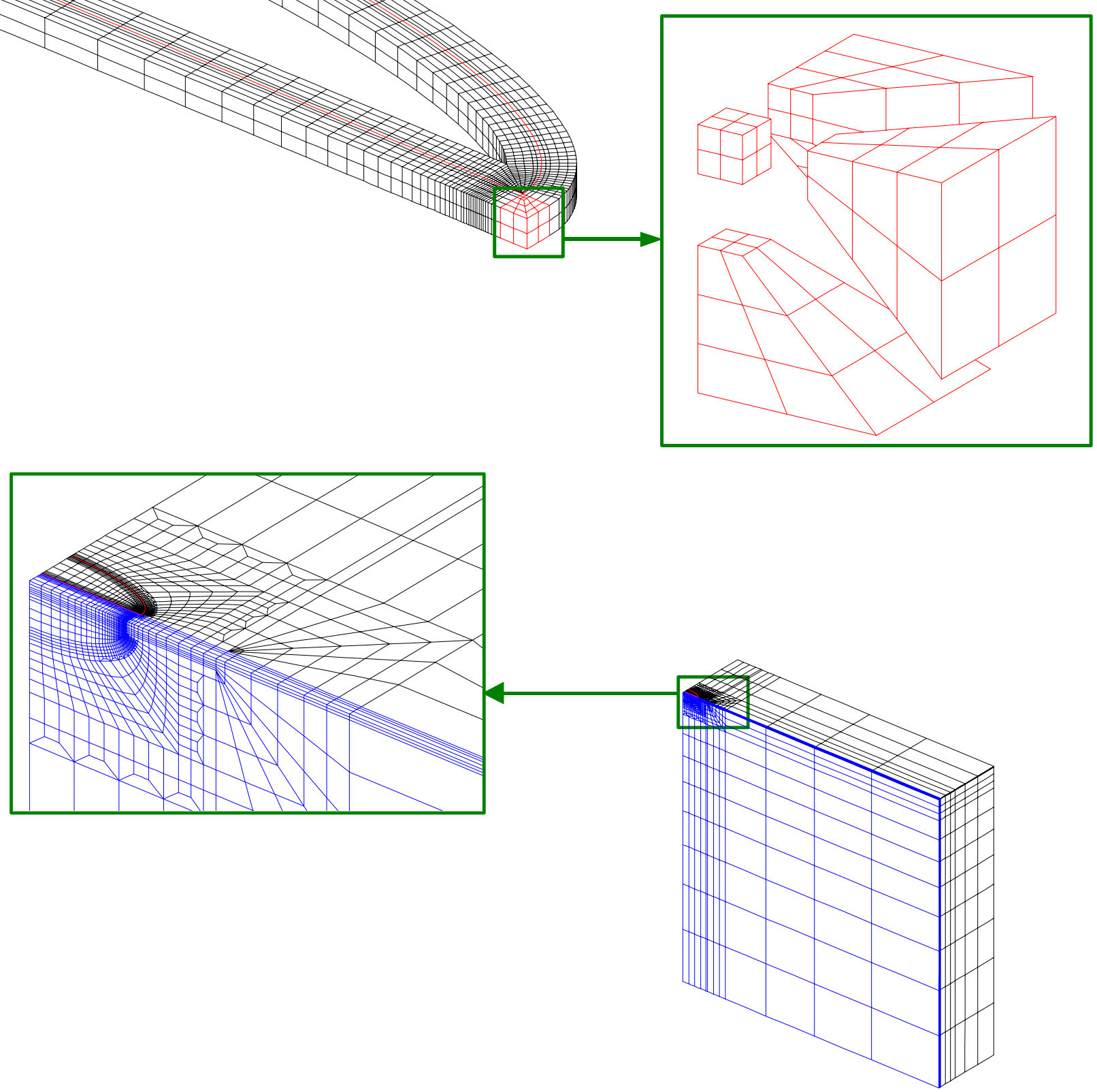

Figure 2. 


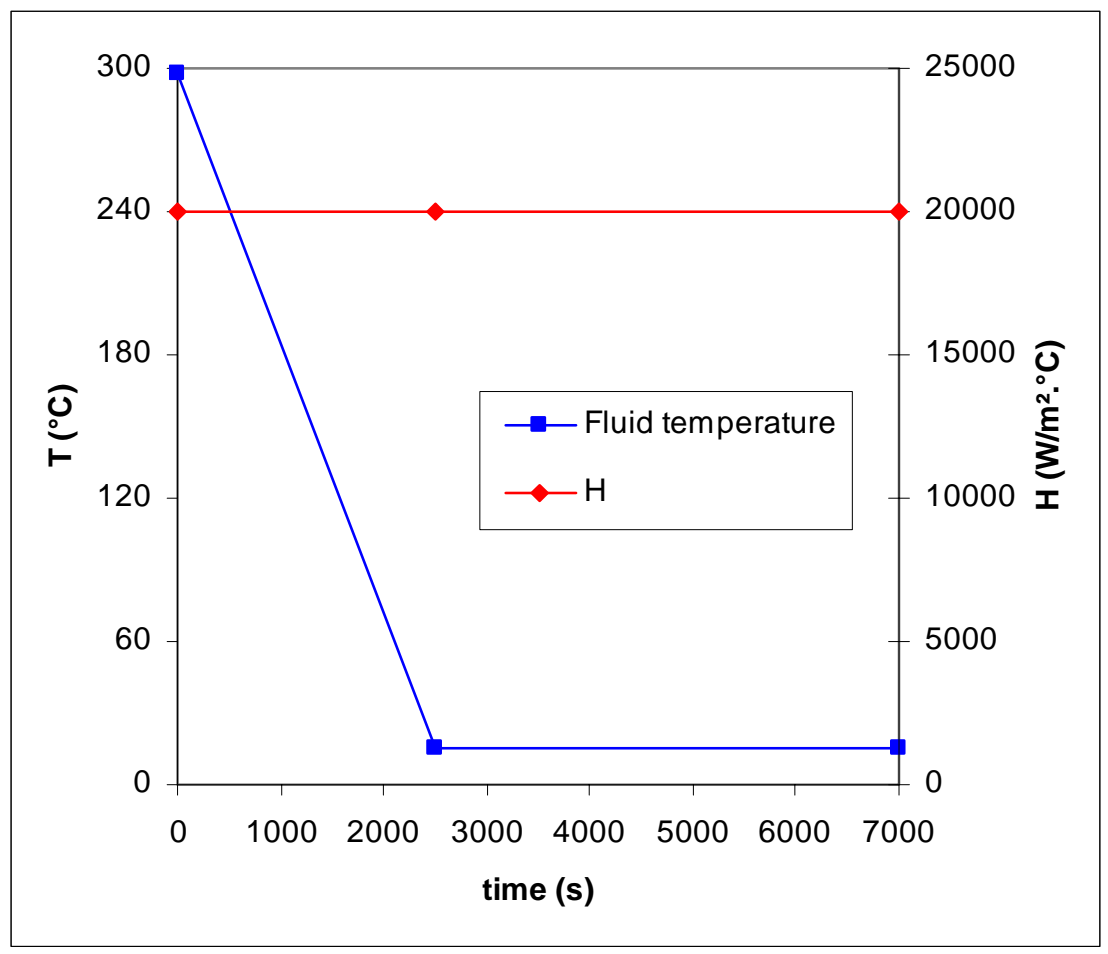

Figure 3 


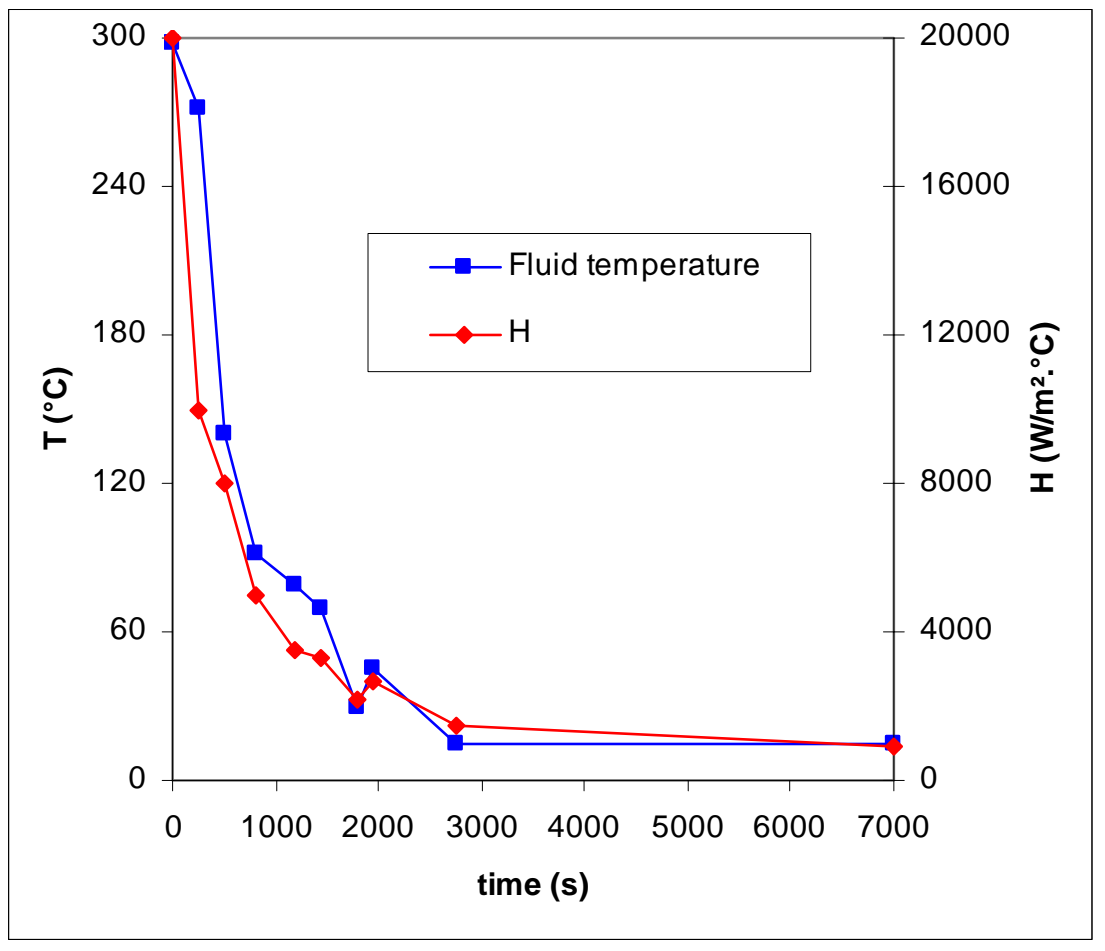

Figure 4 


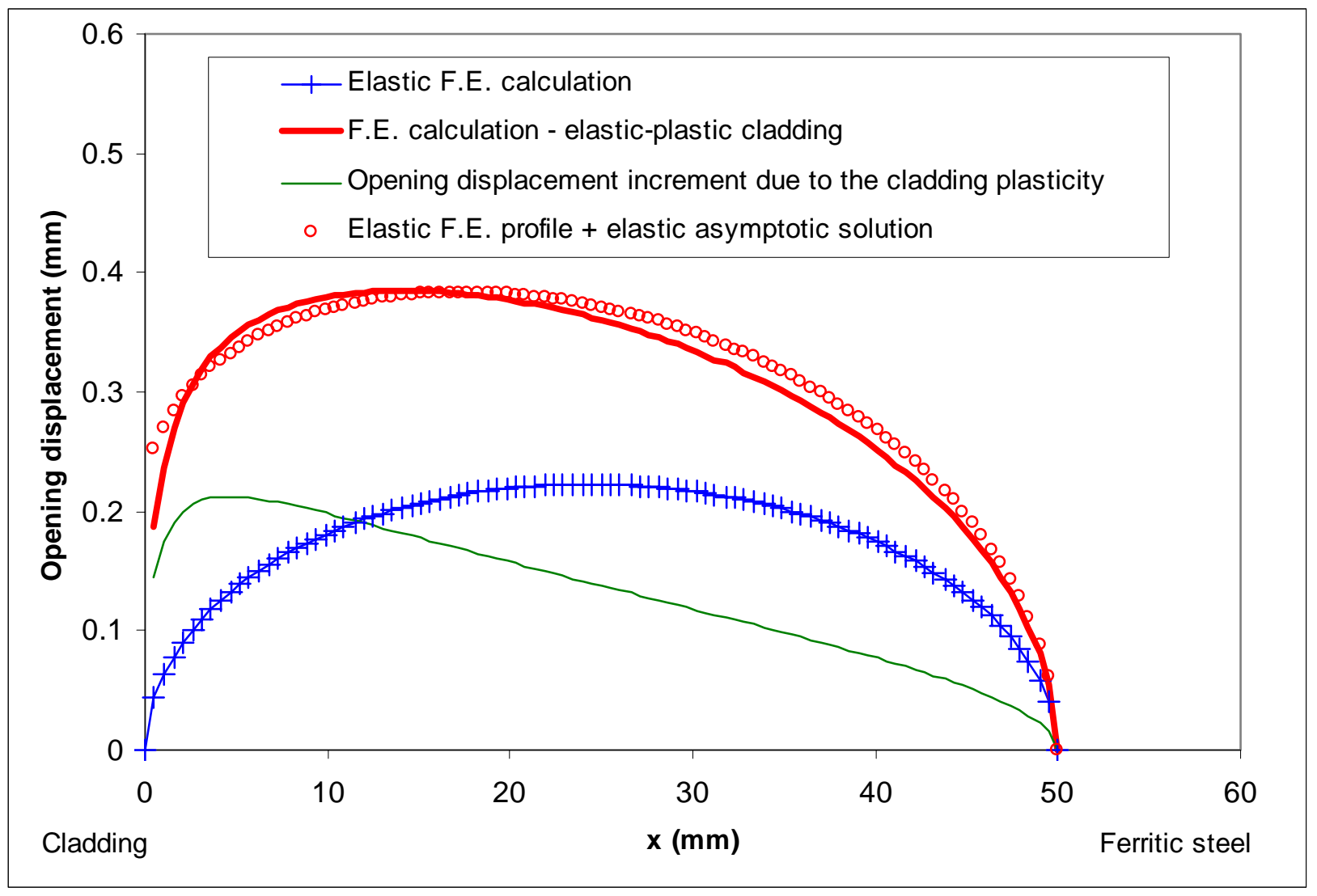

Figure 5 


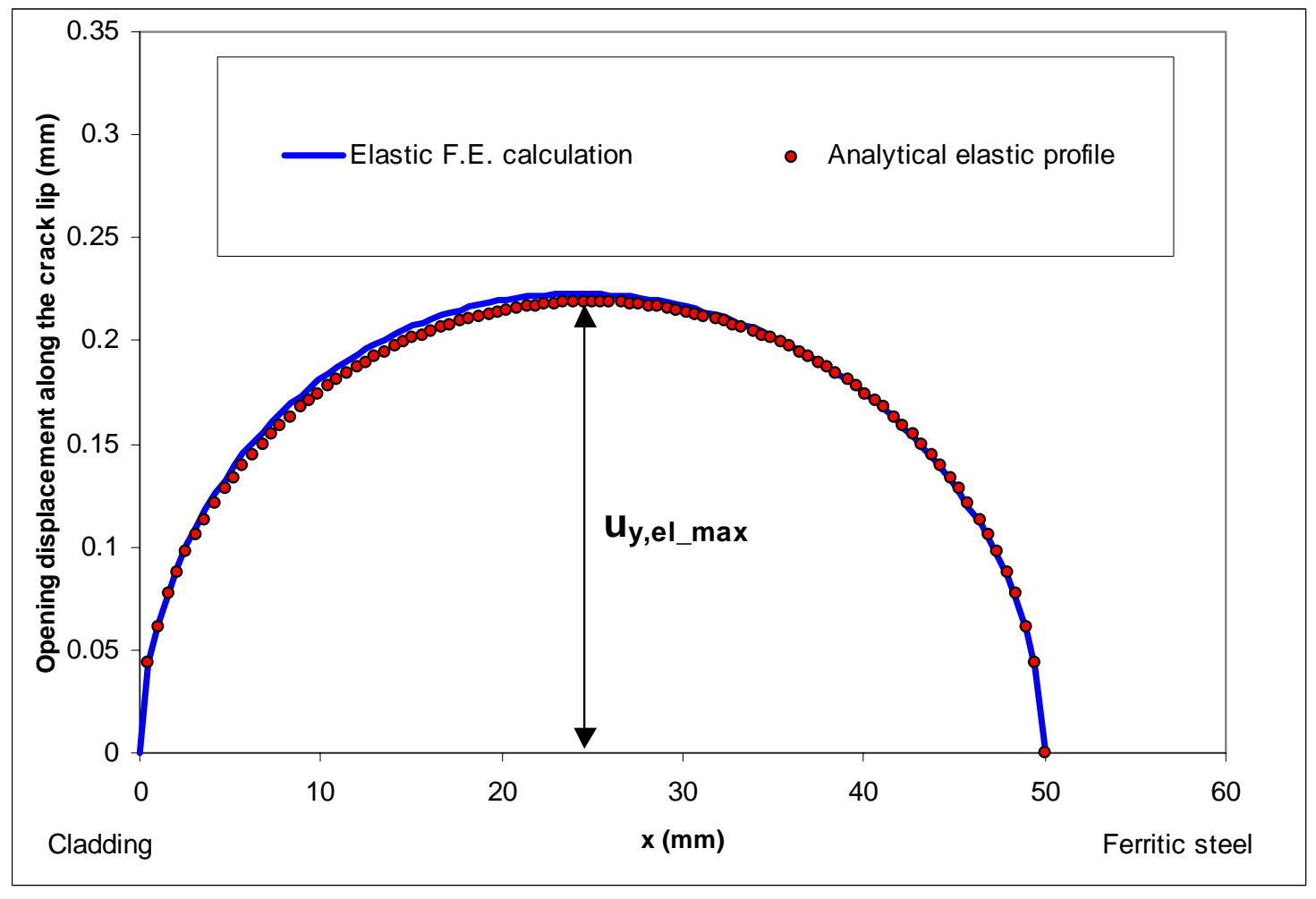

Figure 6 


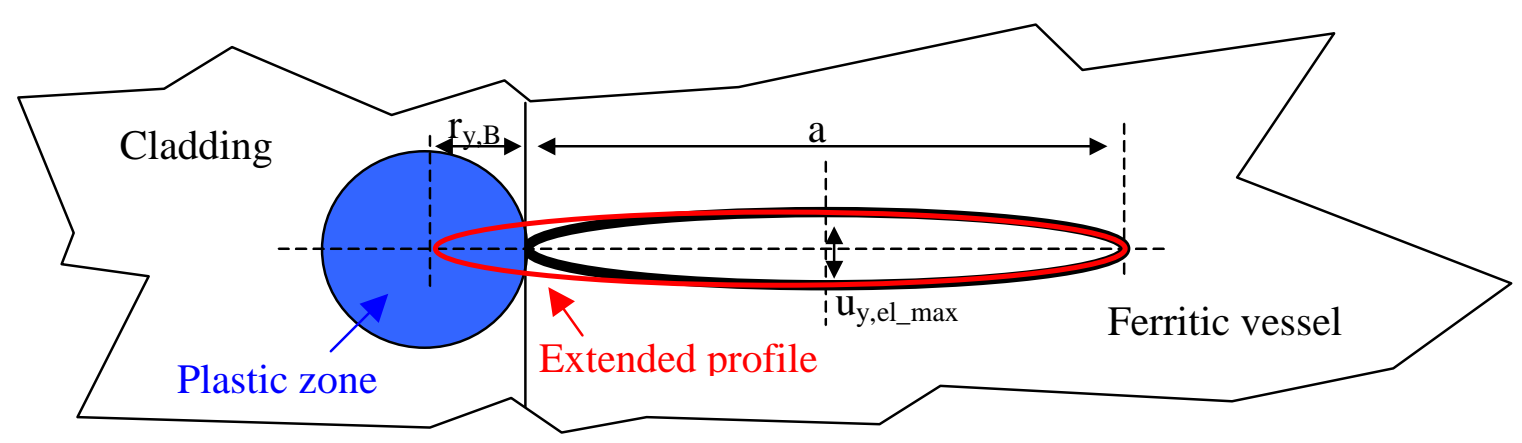

Figure 7 

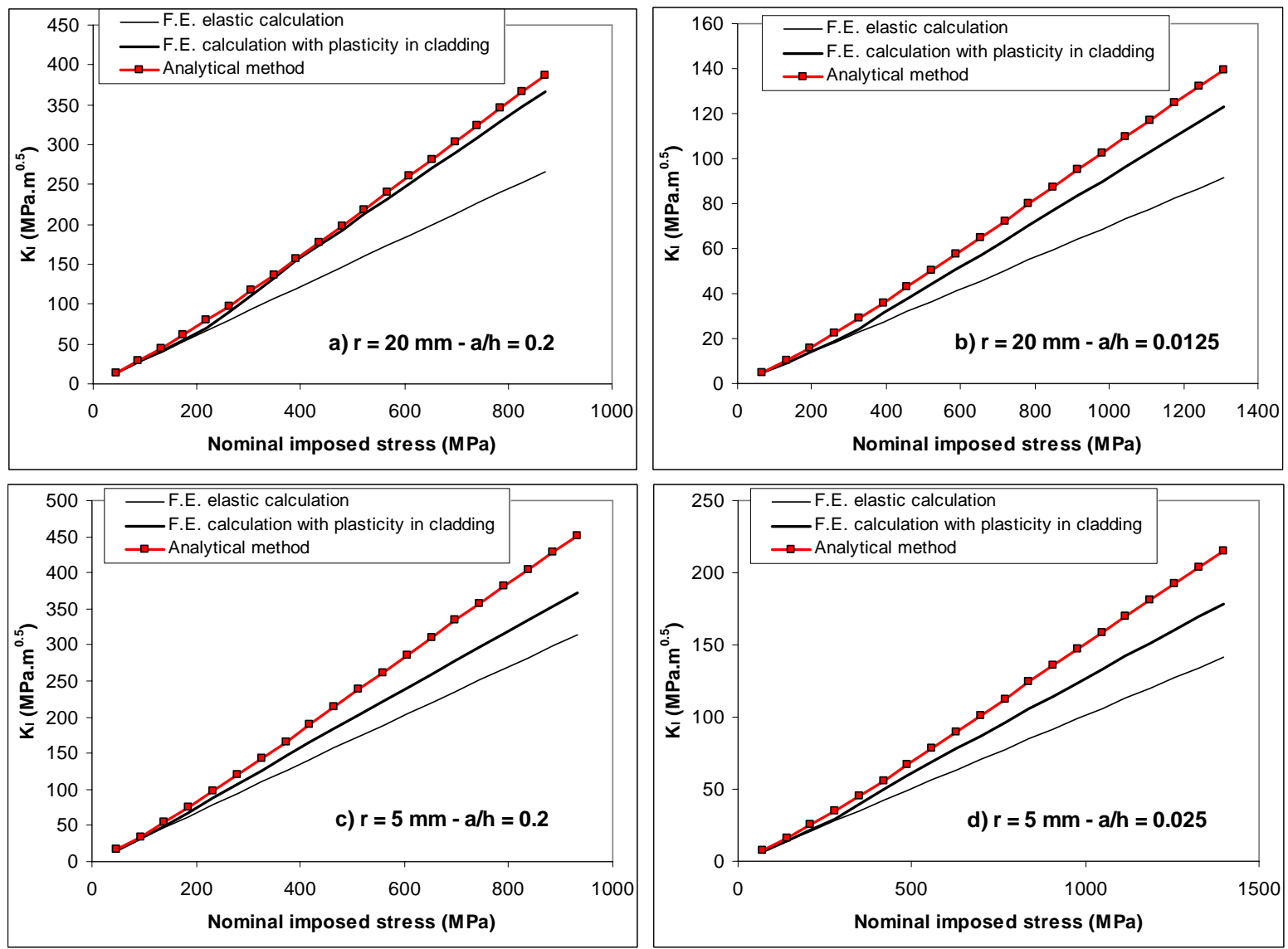

\section{Figure 8}



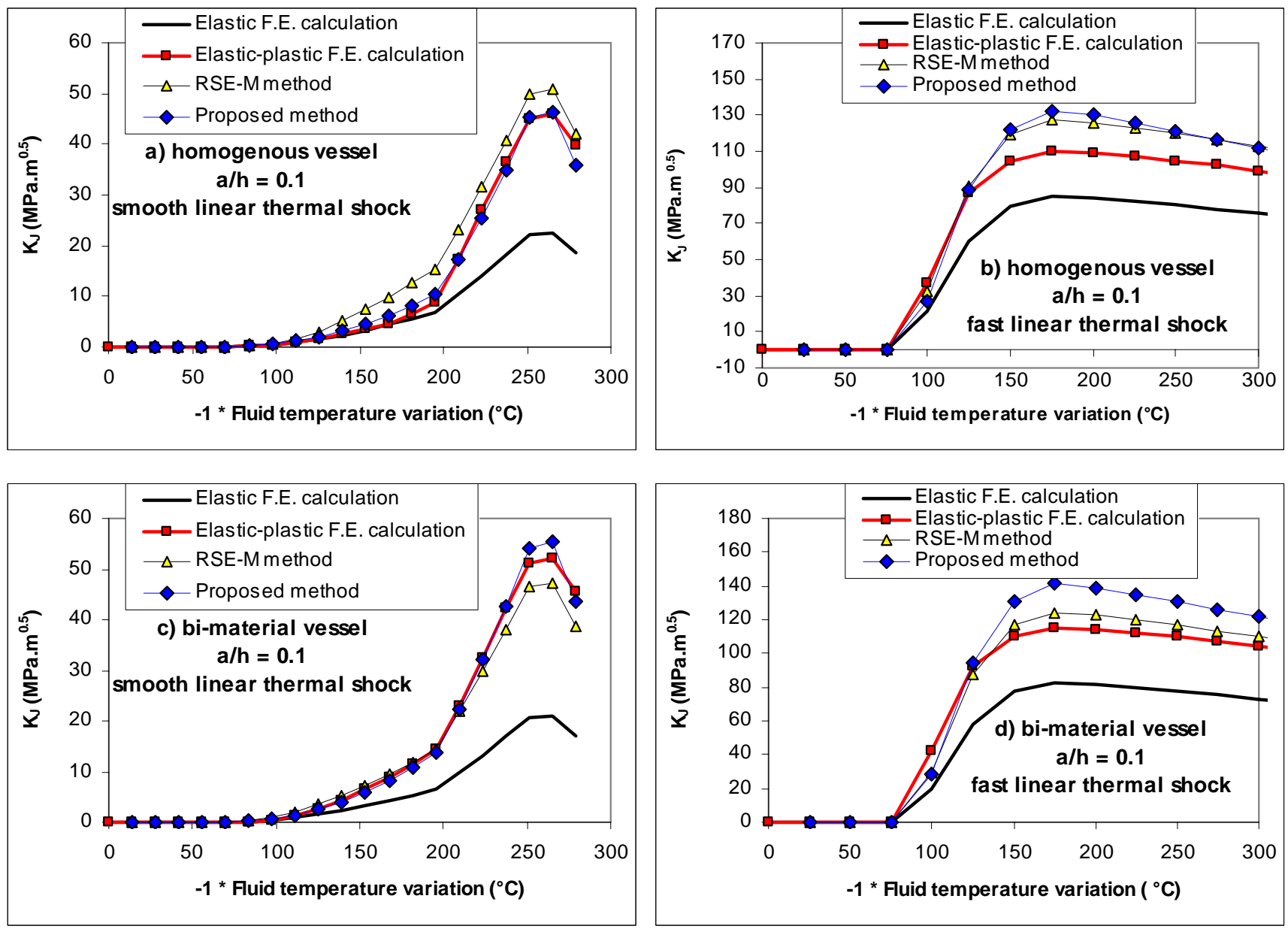

Figure 9 


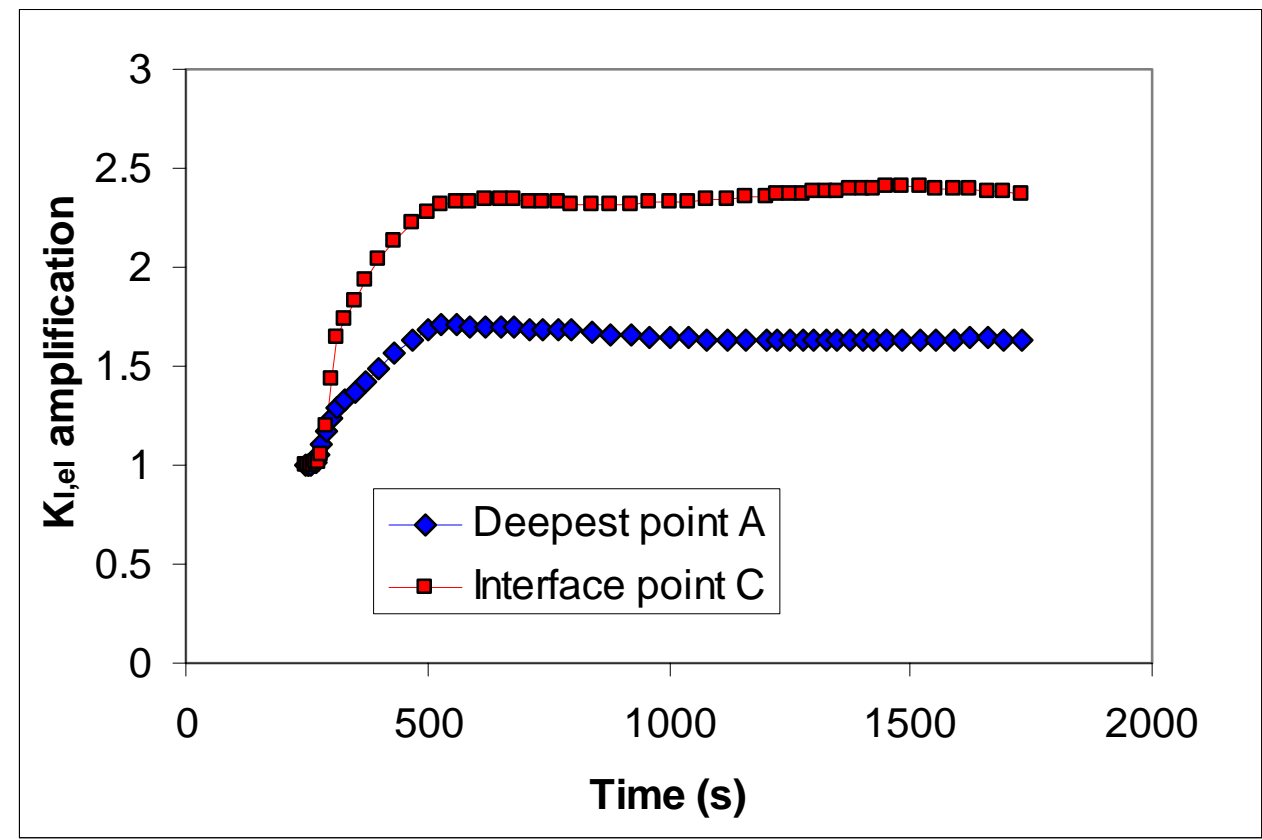

Figure 10 


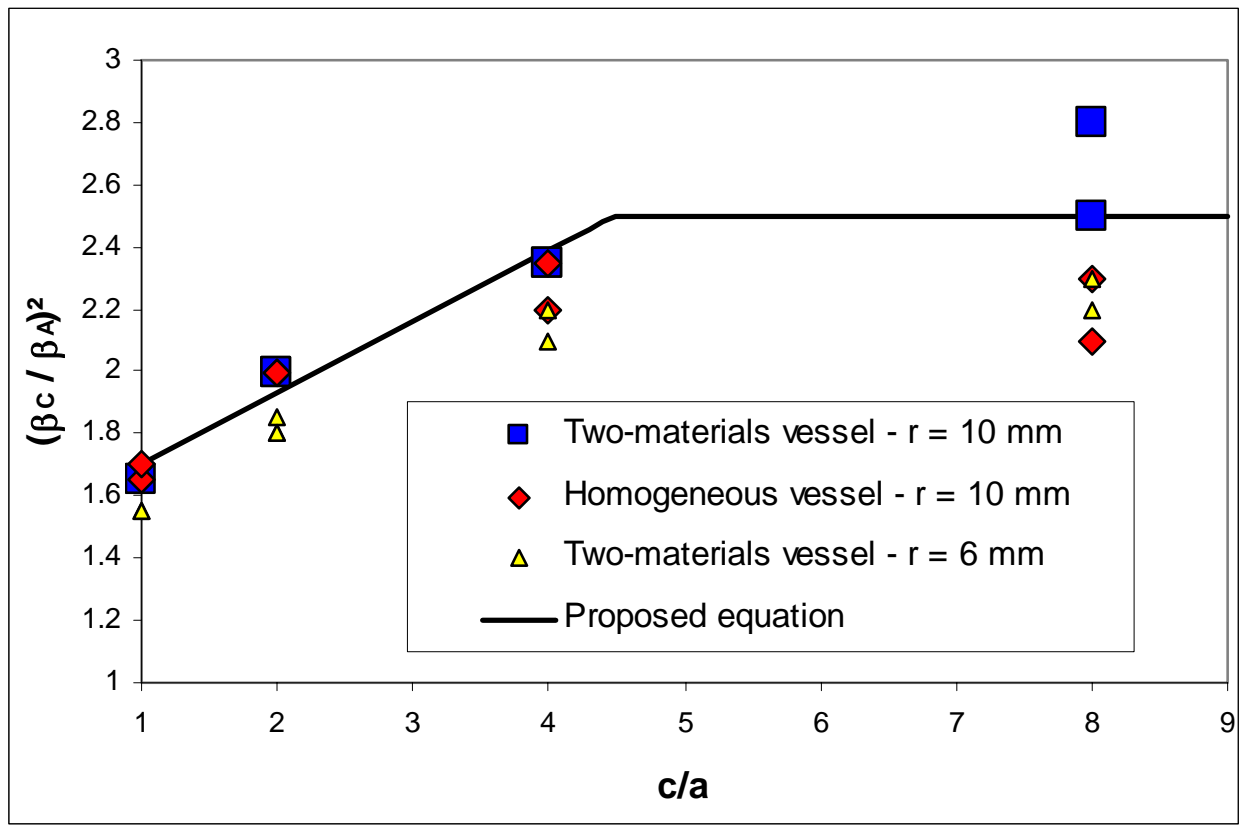

Figure 11 

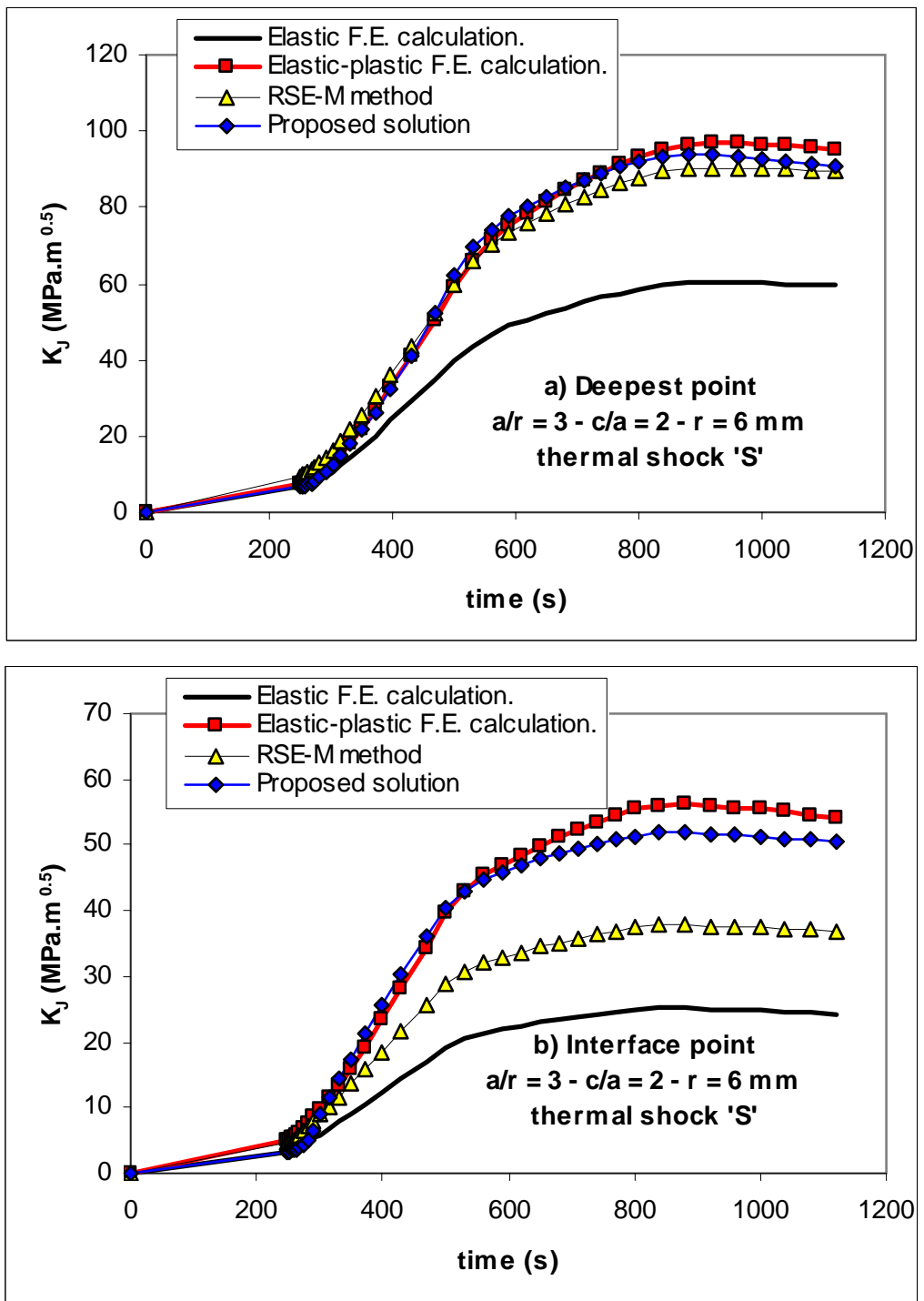

Figure 12 

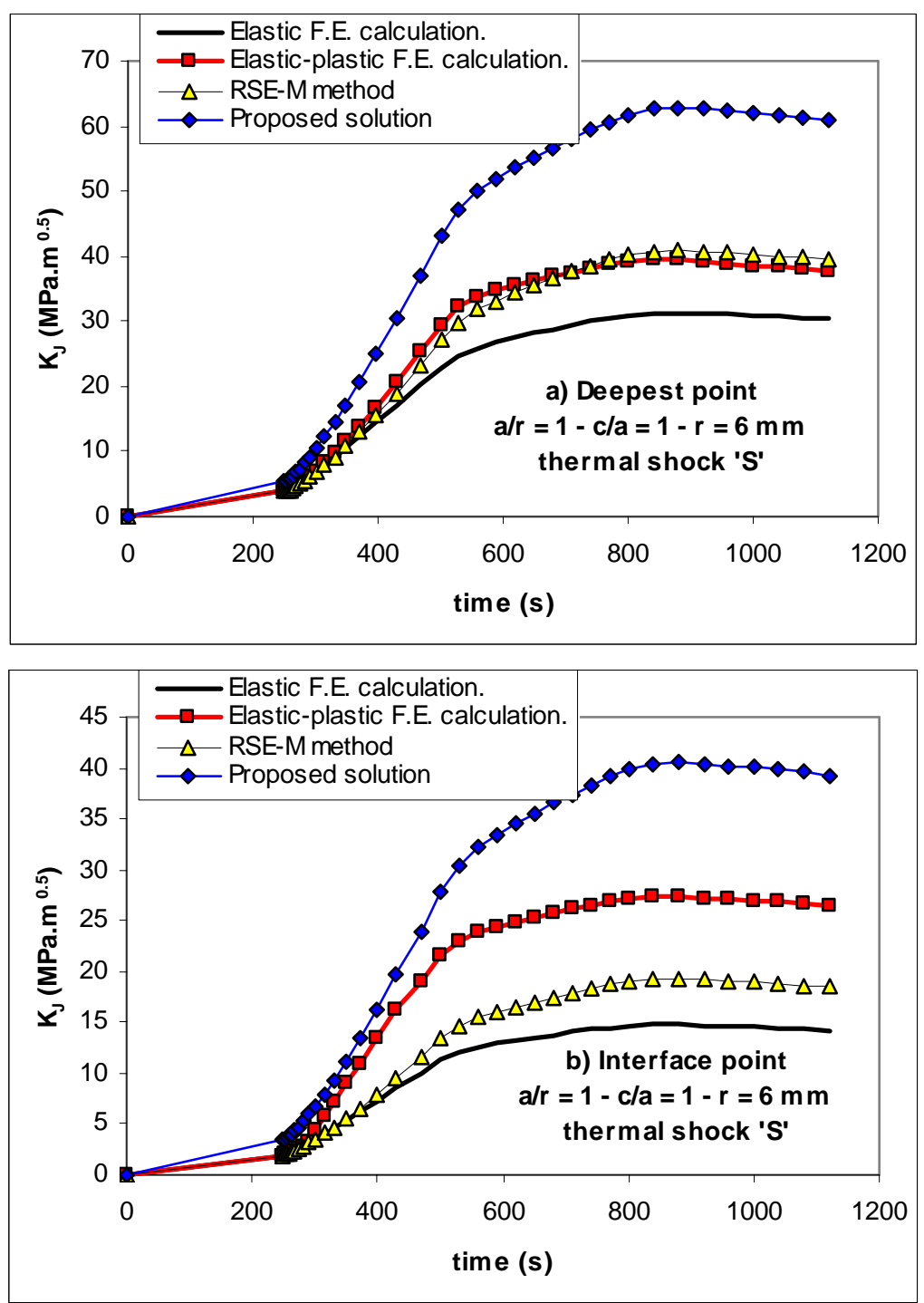

Figure 13 

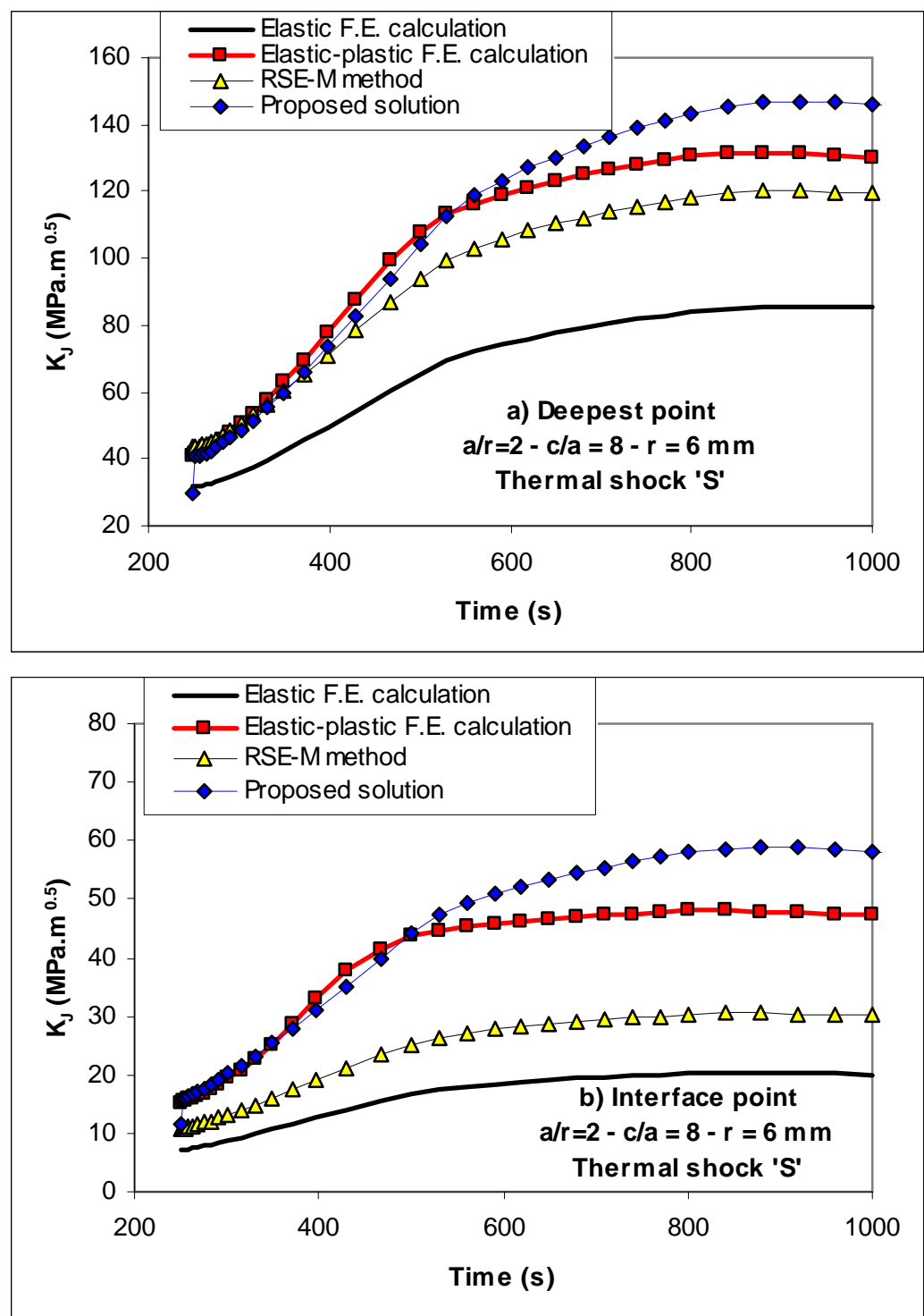

Figure 14 